\begin{abstract}
Title of Document:

EARLY PHONOLOGICAL PREDICTORS OF TODDLER LANGUAGE OUTCOMES

Kayla Nicole Gerhold, Master of Arts, 2015

Directed By:

Dr. Nan Bernstein Ratner, Department of Hearing and Speech Sciences

Several studies have explored relationships between children's early phonological development and later language performance. This literature has included a more recent focus on the potential for early vocalization profiles in infancy to predict later language outcomes, including those characterized by delay or disorder. The present study examines phonetic inventories and syllable structure patterns in a large cohort of infants as they relate to expressive language outcomes at 2 years of age. Results suggest that as early as 11 months, phonetic inventory and mean syllable structure level are related to two year expressive language outcomes (MLU, MCDI, and types). If specific patterns of production can be established for a typically-developing population then this will additionally inform clinical decisionmaking. Possible applications are discussed.
\end{abstract}




\title{
EARLY PHONOLOGICAL PREDICTORS OF TODDLER LANGUAGE OUTCOMES
}

\author{
By \\ Kayla Nicole Gerhold \\ Thesis submitted to the Faculty of the Graduate School of the \\ University of Maryland, College Park, in partial fulfillment \\ of the requirements for the degree of \\ Master of Arts \\ 2015
}

\author{
Advisory Committee: \\ Dr. Nan Bernstein Ratner Chair \\ Dr. Rochelle Newman \\ Dr. Yi Ting Huang
}




\section{Acknowledgements}

This research is supported by an NSF grant (NSF BCS 074512) to Rochelle Newman and Nan Bernstein Ratner. I would like to express a deep appreciation to Dr. Nan Bernstein Ratner, who has provided undying support and guidance over the last several years. I would also like to thank Dr. Rochelle Newman and Dr. Yi Ting Huang for their direction and collaboration. Special thanks go to Dr. Yvan Rose for his endless support, guidance, and teaching on how to use PHON. I'd also like to thank Brain MacWhinney for his computational help. Your assistance made this research project possible. I am also grateful for Daniele Raneri for her contributions

to this paper, and to my friends and family who have supported me through all of my failures and successes, especially Stephen Grossman. I will be forever grateful for what you have helped me achieve. 


\section{Table of Contents}

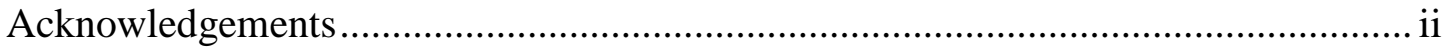

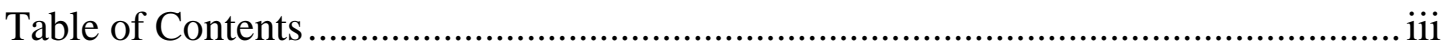

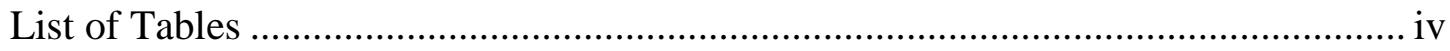

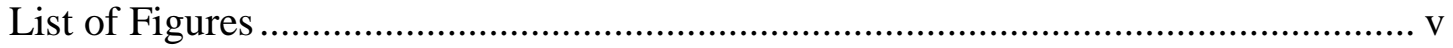

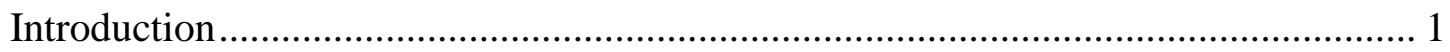

An overview of typical phonological development ............................................. 1

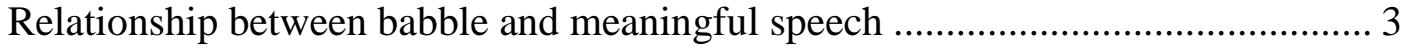

Phonological behaviors and child language performance ................................... 5

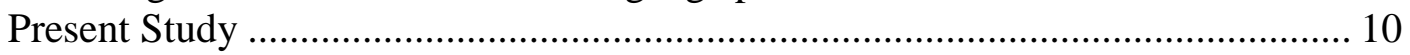

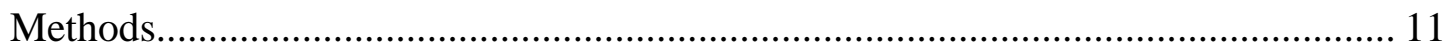

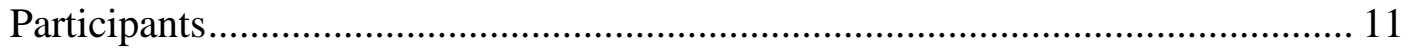

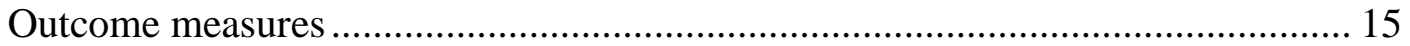

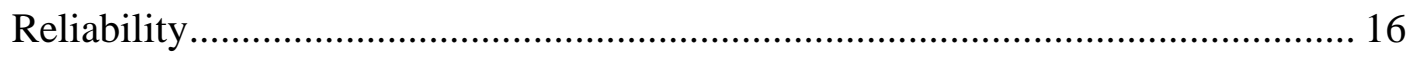

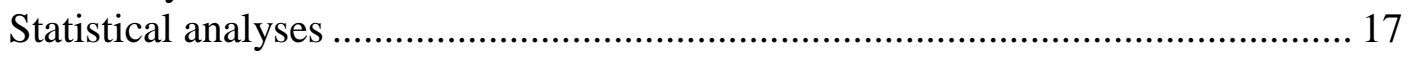

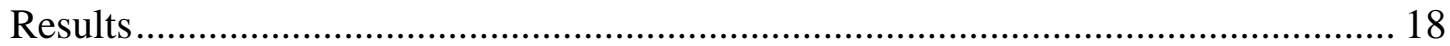

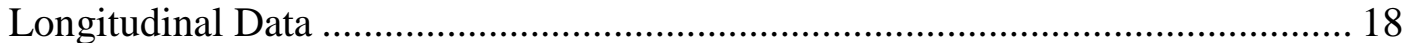

Relationship between phonological variables and 24-month language outcomes.. 20

Group comparisons of 24-month language outcomes ..................................... 25

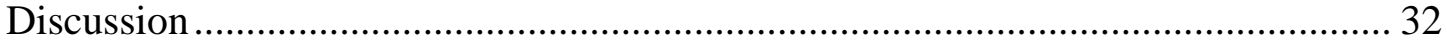

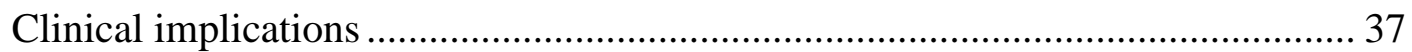

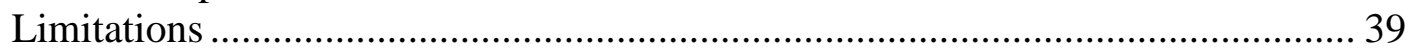

Directions for future research ................................................................. 40

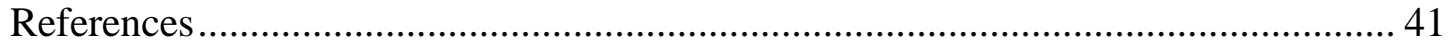


Table 1: Stages of vocal development ............................................................... 2

Table 2: Summary of past studies examining phonological variables relating to

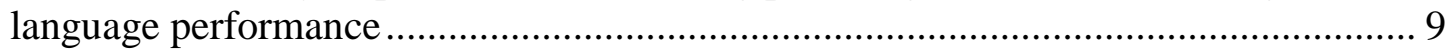

Table 3: Growth of Inventory across Age Intervals................................................ 19

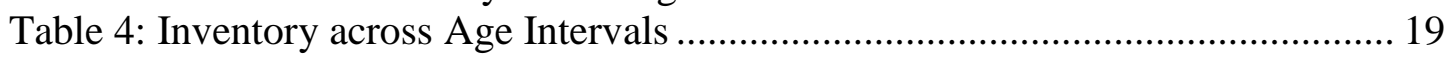

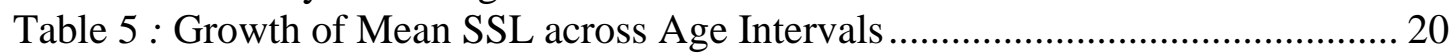

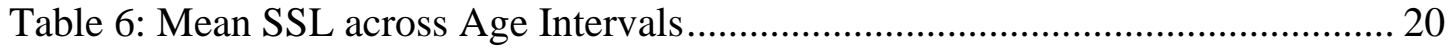

Table 7: 18 month Correlations between expressive language outcomes ................. 21

Table 8: 11 month Correlations between expressive language outcomes ................. 23

Table 9: 7 month correlations between expressive language outcomes .................... 24

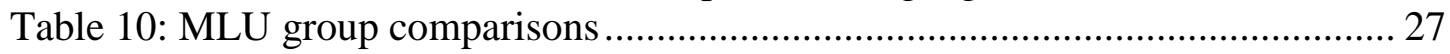

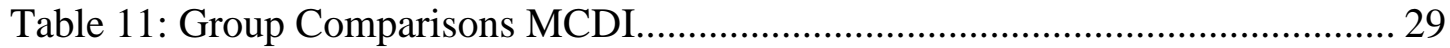

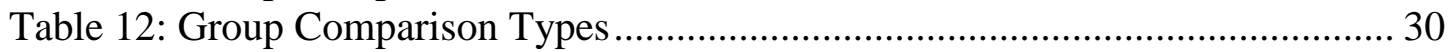




\section{List of Figures}

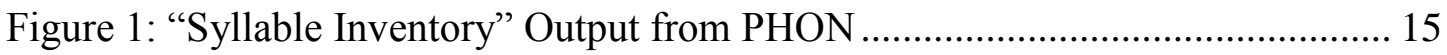

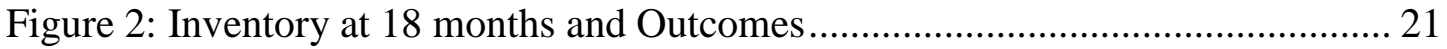

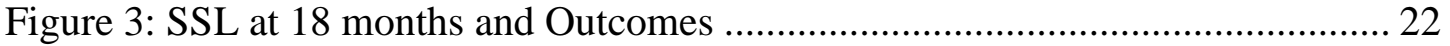

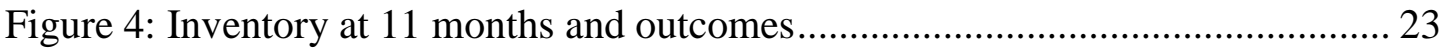

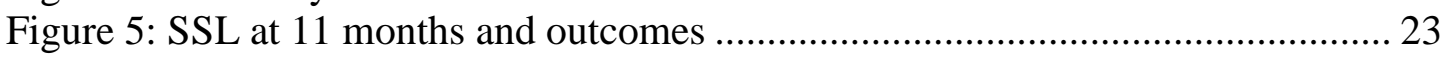

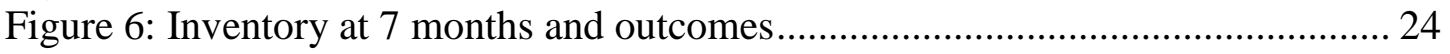

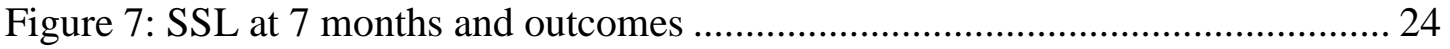

Figure 8: 7 month MLU group comparisons: Inventory and Mean SSL ................... 27

Figure 9: 11 month MLU group comparisons: Inventory and Mean SSL ................. 27

Figure 10: 18 month MLU group comparisons: Inventory and Mean SSL ................ 28

Figure 11: 7 month MCDI group comparisons: Inventory and Mean SSL ............... 29

Figure 12: 11 month MCDI group comparisons: Inventory and Mean SSL ............. 29

Figure 13: 18 month MCDI group comparisons: Inventory and Mean SSL ............. 30

Figure 14: 7 month types group comparisons: Inventory and Mean SSL ................. 31

Figure 15: 11 month types group comparisons: Inventory and Mean SSL ............... 31

Figure 16: 18 month types group comparisons: Inventory and Mean SSL ............... 31 


\section{Introduction}

Over the last fifty years, researchers have found that phonological abilities in infancy can describe and/or predict later language performance and later language outcomes. Specifically, phonetic inventories and syllable structure patterns have been used to describe delayed and/or disordered language profiles. A recurring research question is whether a child's early phonological abilities can be predictive of language performance and/or outcomes at a later time.

\section{An overview of typical phonological development}

To ground the study hypotheses, we will briefly review what is known about the course of early phonological development. Phonological development has both cognitive-linguistic and biological-physiological components. A child must have the motor (physiological) capabilities to produce accurate approximations of words in the native language, as well as perceptual access to the ambient language targets. In addition, the cognitive-linguistic component requires that the child learn the linguistically meaningful sounds (phonemic inventory) and phonotactic rules of the ambient language and consolidate the process of remembering, storing, organizing and retrieving words from the mental lexicon (Stoel-Gammon \& Sosa, 2007). 
Table 1: Stages of vocal development

\begin{tabular}{lll}
\hline Stages of Vocal Development & Vocal Productions & Age Ranges \\
\hline 1. Phonation Stage & $\begin{array}{l}\text { Quasivowels; } \\
\text { glottal }\end{array}$ & Birth- 2 months \\
2. Primitive Articulation Stage & $\begin{array}{l}\text { Cooing: } \\
\text { articulators } \\
\text { becomes more } \\
\text { coordinated with } \\
\text { phonation }\end{array}$ & \\
& 2-3 months \\
& $\begin{array}{l}\text { Full vowels; } \\
\text { raspberries; } \\
\text { marginal babbling }\end{array}$ & \\
3. Expansion Stage & $4-5$ months \\
& & \\
& $\begin{array}{l}\text { Well-formed } \\
\text { canonical } \\
\text { syllables, } \\
\text { reduplicated }\end{array}$ & \\
\hline
\end{tabular}

Oller, Eilers, Neal \& Schwartz (1999) elaborate four stages of phonological development, as originally proposed by Oller (1980) (see Table 1). Vegetative sounds (i.e. coughing, sneezing, burping, etc.) and fixed vocal signals (i.e. crying, laughter, moaning, etc.) are treated separately from the vocal productions that are specific precursors to speech. The phonation stage occurs during the first two months of life, a period during which quasivowels are produced frequently. Quasivowels are produced with the vocal tract at rest with smooth onset and even sound quality of speech. The primitive articulation stage occurs between two and three months of age; the articulators become more coordinated with phonation and consonant-like sounds begin to be produced. In the expansion stage, infants begin to produce fully resonant 
vowel sounds and begin to purposefully experiment with variations in utterance, pitch, and intensity. In addition, they begin to produce a combination of consonant-like and vowel-like sounds called marginal babbling. During canonical babbling, which occurs between 6 and 8 months of age, infants begin to produce canonical syllables that have the prosody and syllable structure characteristics that are similar to that of adult-like speech in the ambient language. The sounds and syllable structures that children produce during the canonical stage often carry over into the child's preferences for first word productions. Across these four stages, it is clear that there is an element of continuity, for each stage incorporates components of speech: phonation, articulation and consonant-vowel combinations (Oller \& Lynch, 1992).

\section{$\underline{\text { Relationship between babble and meaningful speech }}$}

The literature tracking profiles of infant and toddler phonological development has evolved in major ways over the last fifty years. In a seminal paper, Jakobson (1941) proposed that there was discontinuity between early vocalizations in infancy and later meaningful speech production. He hypothesized that "true" phonological acquisition begins when the child recognizes that speech sounds have meaning in the ambient environment and contended that all sounds produced by the infant prior to this time were truly prelinguistic, in that they did not contribute meaningfully to linguistic development. He also believed that there was a 'silent period' that marked the transition between meaningless babble and the attempted production of true adult-like speech. Although several researchers have supported Jakobson's discontinuity hypothesis, others have challenged this school of thought. Over the years, research has shown that infant phonological development appears to be systematic, purposeful, and continuous (Oller, Wieman, Doyle, \& Ross, 1976; Stoel-Gammon, 1985; Vihman, Macken, Miller, 
Simmons, \& Miller, 1985; Vihman \& Greenlee, 1987). Oller et al. (1976) was one of the first studies to implement more precise methodologies of infant recording and transcription, allowing for calculations of actual frequencies of vocalization types (tokens of vocal activity), as opposed to anecdotal data that concentrated more extensively on unique types of vocalizations observed in the child's output. The authors predicted that the babbling patterns they would observe would be consistent with and reflect the well-documented phonological processes in 'meaningful' child speech (i.e., due to the universality of cluster reduction in early child speech, there would be a greater amount of singleton consonants; due to final consonant deletion, there would be more consonants in the initial position compared to final position of babbled utterances). Data included a total of ten audio recordings of child babbling, five children between the ages of $1 ; 0$ and $1 ; 1$, and five children between $0 ; 6$ and $0 ; 8$.

Results provided strong evidence to support the continuity hypothesis, in that the babbled utterances observed exhibited many of the same preferences for elements and sequences found in meaningful speech. Others have also argued that there is little support for the discontinuity hypothesis and that there is, in fact, a systematic transition from early vocal development into meaningful language production (Vihman, Macken, Miller, Simmons, \& Miller, 1985; Vihman \& Greenlee, 1987). Vihman \& Greenlee (1987) found a persistence of individual phonological differences among seven typically-developing children observed at 1 year and 3 years of age; though there were individual differences, the proportion of vocalizations with consonants was found to predict phonological ability and language skills at age three and that this measure reflects "sensitivity to language-like segments and syllables". 
Observed continuity of babbling into meaningful speech suggests that phonological variables may predict later language outcomes; if variable profiles of either type or quantity of early vocalizations can be found to presage differences in the pacing or later abilities of young language learners, it may enable us to identify children at-risk for language delay/disorder in order to intervene earlier and more effectively.

A child's first words have been shown to be driven by his/her early phonetic inventories and syllable structure preferences. Previous research on the relationship between babble and early speech has focused on whether the same sounds are produced in both stages. Vihman, Macken, Miller, Simmons, and Miller (1985) found that the distribution of consonants, length of vocalization and phonotactic structure of babbled sounds for nine infants starting at nine months and followed until sixteen months of age were virtually identical to those of their first words; however, only nine participants were available for analysis. Infants have also been found to produce a higher proportion of favored babble sounds in early words, even in contexts where they do not belong (i.e., as errors for target sounds that do not appear in the adult word ) and omit/delete non-favored sounds (Oller, Wieman, Doyle \& Ross, 1975). Such findings suggest that prelinguistic vocalizations may be predictive of later language attempts.

\section{Phonological behaviors and child language performance}

There have been two main conceptual approaches to the relationship between early prelinguistic vocalizations and speech and language production. One of these is the so-called "transactional hypothesis": both child characteristics and mediation from the environment (usually adult responsiveness) may account for child language outcomes. Mothers often respond 
to prelinguistic vocalizations as being meaningful (Harding, 1984), leading to the idea of possible parental mediation of infants' prelinguistic vocalizations and later language production. McCune (1992) suggested that adults begin to attribute meaning to canonical babbling and thus respond to these vocalizations with communicative intent. This feedback may lead the child to make connections between the subject of communication and the adult word, further facilitating language development.

In contrast, a separate body of research has explored a more child-driven model; as previously discussed, it has been well established that there is a continuous relationship between prelinguistic vocalizations and later spoken language (Oller et al., 1976; Stoel-Gammon, 1985; Vihman, Macken, Miller, Simmons, \& Miller, 1985; Vihman \& Greenlee, 1987). One childdriven hypothesis to explain why children with larger phonetic inventories and more developed phonological skills make earlier strides in language development is that a child who vocalizes more may have a larger sound inventory to map onto meaning (Stoel-Gammon, 1989). Furthermore, infants who have more varied babbling profiles may have more highly developed motor skills than those with less babbling (Locke, 1989). It may be difficult to separate these interactional from child-driven hypotheses, as it is also likely that infants who produce a wider variety of speech-like efforts may provide mothers with greater opportunities to treat them as communicative (Rescorla \& Ratner, 1996).

Several studies have found conclusive evidence that the quality and quantity of prelinguistic vocalizations can predict later language outcomes (Oller, Eilers, Neal, Schwartz, 1999; McCathren, Yoder \& Warren, 1999). For example, late onset of canonical babbling may predict a delay in the onset of speech production. Oller, Eilers, Neal \& Schwartz (1999) followed-up 
with eight infants who had not started babbling by ten months of age and found that they had smaller expressive vocabularies (indicated by performance on MCDI) at 18, 24 and 30 months than a comparison group of ten infants who had started canonical babbling by ten months of age. In another study, McCathren, Yoder, \& Warren (1999) found that vocalization rate and use of consonants at 17-34 months were highly correlated with vocabulary size examined 12 months later in a group of fifty-eight (58) toddlers with a range of etiologies.

Other studies have been able to use phonological variables to compare disordered or delayed profiles to a typically-developing (TD) population. Some studies have found that, compared to typically-developing peers, late-talkers display less complex syllable structures and less consonantal babble (Whitehurst, Smith, Fischel, Arnold, \& Lonigan, 1991; Paul \& Jennings, 1992; Rescorla \& Ratner, 1996). Rescorla \& Ratner (1996) found that 30 late talking toddlers at 24 months of age vocalized less, had smaller phonetic inventories, and used simpler syllable shapes compared to typically developing peers. Another study examined thirteen toddlers at familial risk for reading impairment and their babbling between the ages of eight and nineteen months of age. Toddlers who later were diagnosed as having a reading disorder (RD) produced a lower proportion of canonical babbling and less complex syllable structures than those not at risk for RD (Lambrecht, Roberts, Locke \& Tozer, 2010). Children with Expressive Specific Language Impairment (SLI-E) were found to produce less complex syllable structures (defined as shapes with more than one consonant, final consonants and consonant clusters) compared to TD developing peers at 24 and 36 months of age (Pharr, Ratner \& Rescorla, 2000). Furthermore, bilingual children with Specific Language Impairment (SLI) and language delay (LD) have shown delayed acquisition of syllabic structures and depressed phoneme inventory compared to age-matched bilingual-speaking peers (Aguilar-Mediavilla, Sanz-Torrent, \& Serra-Raventos, 
2002). In a meta-analysis, Morris (2010) reviewed six of the studies discussed above to determine the clinical application of mean SSL to describe phonological abilities of children under three years of age. She determined that the literature supports the concept that mean syllable structure level (SSL) can be a reliable and informative measure of phonological abilities during language development.

Although promising in their suggestion that early speech behaviors may predict variation in language outcomes and/or performance compared to TD peers, the individual studies to date are characterized by small population size and/or a limited age window for observation and follow-up (See Table 2). In sum, the literature suggests that a child's phonetic inventory and syllable structure patterns in infancy are related to later achievements in language development. There is limited exploration as to how early a child's phonological abilities can be predictive or related to their later language. Studies have suggested that as early as nine months of age, there is similarity between inventory and syllable structure patterns and those seen in a child's first words (Vihman \& Greenlee, 1987; Vihman, Macken, Miller, Simmons, \& Miller, 1985); however, the literature that relates a child's phonological abilities with later language outcomes has focused on children aged 17-36 months (McCathren, Yoder \& Warren, 1999;Rescorla \& Ratner, 1996; Lambrecht, Roberts, Locke \& Tozer, 2010; Pharr, Ratner, \& Rescorla, 2000). Additional exploration into the relationship between phonological abilities and later language outcomes at ages prior to what has been previously explored, could allow for earlier monitoring of children demonstrating profiles at-risk for delay or disorder. There is growing effort in the field of child language development to determine patterns of typical development in order to further inform profiles of delay or disorder to intervene as soon as possible. 
Table 2: Summary of past studies examining phonological variables relating to language performance

\begin{tabular}{|c|c|}
\hline Study & $\begin{array}{l}\text { Number of } \\
\text { Children }\end{array}$ \\
\hline
\end{tabular}

Vihman \& Greenlee (1987)

Vihman, Macken, Miller, Simmons \& Miller (1985)

Oller, Eilers, Neal \& $\quad 8$ Schwartz (1999)

McCathren, Yoder \& 58 Warren (1999)

Rescorla \& Ratner (1996)

30

24 months

17-34 months Vocalization rate \& consonant use correlated with vocabulary size 12 months later in children with mild to moderate developmental delay

months) found to have smaller
expressive vocabularies at 18,24 \& 30 months phonotactic structure were similar to their first words

Late onset of babbling (10 months) found to have smaller

Lambrecht, Roberts, 13 Locke \& Tozer (2010)

13

8-19 months

Toddlers who were later diagnosed w/ a RD had lower proportion of canonical babbling 
Fasolo, Majorano, \& 24

D'Odorico(2008)

Pharr, Ratner, Rescorla (2000)
20 months

Compared to TD control group, LT (late-talkers) had lower phonetic complexity and number of consonantal types

$24 \& 36$ months
Compared to TD group, SLI-E produced fewer syllable shapes with more than one consonant, final consonants, and consonant clusters

\section{$\underline{\text { Present Study }}$}

The available evidence suggests that a child's prelinguistic vocalizations, specifically phonetic inventory and syllable structure patterns, may potentially predict later language outcomes. Additional exploration of the relationship between phonetic inventories and syllable structure patterns and later language outcomes can expand on current findings and test the generalizability of the claims made on the basis of smaller studies. As part of a larger longitudinal study of children's language development, we have the opportunity to further explore children's phonological abilities from seven and a half months of age to 24 months of age. Better understanding of the development of syllable structures and specific phonetic profiles in relation to expressive language outcomes at 24 months of age can expand clinical knowledge of typical development in not-at-risk infants. If a relationship exists between specific syllable structure and phonetic inventories profiles, and later language outcomes this will further 
expand and support the idea that speech production in infancy can predict later language performance, enable early detection of risk factors for delay, and increase the potential for earlier and more effective intervention for language delay and disorder.

We followed 48 infants from 7.5 months to 24 months of age to examine the nature and changes in phonetic inventory and syllable structure patterns over time. This is a relatively large cohort for phonological analyses, as well as a unique age range, starting earlier than most studies reviewed in the preceding section.

We predicted that a child's phonetic inventory of vowels and consonants at 7.5, 10/11, and 18 months will predict 24 month expressive language outcomes in a large cohort of children without risk factors for delayed development. We also predicted that children with more sophisticated or developed syllable structure (larger mean syllable structure level) will show more advanced or higher expressive language skills at 2 years of age. Furthermore, we hypothesized that those children who have superior language outcomes at two years of age will have superior phonetic inventories and mean syllable structure levels at each age interval (7.5, 11, and 18 months) compared to those children who have less superior language outcomes in our sample.

\section{Methods}

\section{$\underline{\text { Participants }}$}

Participants were 48 mother and child dyads who were part of a larger longitudinal study at the University of Maryland. All participants were native English-speakers, and all infants were born within three weeks of their due dates with no previously diagnosed developmental disorders or delays. Each dyad reported to the University of Maryland for scheduled play 
sessions when the child was $7.5,10$ or 11,18 , and 24 months of age. The data from the present study were obtained from each age range.

\section{$\underline{\text { Transcription methods }}$}

Mother-child speech samples were conducted in a sound-treated therapy room. Experimenters instructed parents to play with their infants the way they would at home using a variety of standardized toys selected to encourage mother-child interaction. Each play session was approximately 10-15 minutes in length and was audio-recorded.

Each audio-recorded mother-child play session was originally transcribed using the Codes for the Human Analysis of transcripts (CHAT) developed by the CHILDES project (MacWhinney, n.d.). This program allows an audio or video file to be linked to individual lines in the transcript. All CHAT transcripts were then converted to .xml files in order to be compatible with PHON (Rose, MacWhinney, Byrne, Hedlund, Maddocks, O’Brien, \& Wareham, 2006) and child utterances were transcribed with the International Phonetic Alphabet (IPA). PHON is a software program that allows for a variety of phonological analysis be completed with audio and video transcripts. Similar to Oller, Wieman, Doyle \& Ross (1975), we included only 'speech-like utterances' in our analysis, which includes adult-like approximations of consonants and vowels. In instances of babbled strings, we transcribed the child's utterance using "maximal bracketing" to create the largest possible unit (CVCV or VCVC sequences) to maximize their potential for more advanced syllable shapes, as in Pharr, Rescorla \& Ratner (2000). Other vocalizations such as vocal play (raspberries, squeals, etc.) and non-English sounds and were marked for potential analysis at a later time. 
Utterances were broadly transcribed with IPA using guidelines used in Stoel-Gammon, 1989; Paul \& Jennings, 1992; and Pharr, Ratner \& Rescorla, 2000:

1. A vocalization was defined as a minimum of a voiced vocalic element or a voiced syllabic consonant that occurred on an egressive airstream.

2. Vocalizations that could not be confidently transcribed after five repetitions or were inaudible (e.g., concurrent with maternal speech or toy noise) were eliminated.

3. Screams, cries, coughs, and any other vegetative sounds were excluded.

4. Babbled and non-interpretable utterances were bounded by 1 second of silence, a breath, a noise, or maternal speech.

5. Intonational contours were used to determine the utterance boundary.

Total phonetic inventories were obtained at 7.5 months, 10 or 11 months, and 18 months for each child using the program PHON to run consonant and vowel queries on transcribed utterances. These queries provided a list of all consonants and vowels produced during a session. In order to obtain syllable shapes, we developed a query within PHON called "Syllable Inventory" (See Figure 1). This was designed to output all the syllable shapes produced by the child within one session. 
In order to obtain mean syllable structure level each utterance was assigned a level between 1 and 4, as in Pharr, Ratner \& Rescorla (2000):

Level 1: vocalizations containing a vowel (e.g., [a]), a syllabic consonant (e.g., $[\mathrm{s}]$ ), or a CV syllable in which the only consonant type is a glottal stop (e.g., [Gu]) or glide (e.g., [wi]);

Level 2: vocalizations containing true consonants with a single consonant (e.g., [ba], [vp]) or identical consonants (e.g., [mam], [dædi]) not represented in Level 1; Level 3: vocalizations containing two or more different consonants, not including consonant clusters (e.g., [dOgi], [kvp], [fInI']), and vocalizations containing consonants that differed solely in voicing (e.g., [pvbv]);

Level 4: vocalizations containing consonant clusters (e.g., [brv'], [El\{fvnt]).

Level 4 utterances were combined with Level 3 utterances when calculating mean SSL due to the expected limited production of consonant clusters in our young cohort. SSL is a weighted measure of syllable structure complexity. The total number of each syllable level type was tallied and the Mean Syllable Structure Level was calculated using the following formula: $(\mathrm{SS} 1+(\mathrm{SS} 2 \times 2)+((\mathrm{SS} 3+\mathrm{SS} 4) \times 3)) /(\mathrm{SS} 1+\mathrm{SS} 2+\mathrm{SS} 3+\mathrm{SS} 4)$ 
Figure 1: "Syllable Inventory" Output from PHON

$\begin{array}{lll}\mathrm{CHI} & \mathrm{d} \varepsilon & \mathrm{CV} \\ \mathrm{CHI} & \mathrm{d} ə & \mathrm{CV} \\ \mathrm{CHI} & \mathrm{h} v & \mathrm{CV} \\ \mathrm{CHI} & \mathrm{dit} & \mathrm{CVC} \\ \mathrm{CHI} & \mathrm{det} & \mathrm{CVC} \\ \mathrm{CHI} & \mathrm{d} \text { t } & \mathrm{CVC} \\ \mathrm{CHI} & \text { det } & \mathrm{CVC} \\ \mathrm{CHI} & \text { dæet } & \mathrm{CVC} \\ \mathrm{CHI} & \text { dade } & \mathrm{CVCV} \\ \mathrm{CHI} & \text { dædi } & \mathrm{CVCV} \\ \mathrm{CHI} & \text { didr } & \mathrm{CVCV} \\ \mathrm{CHI} & \text { bæho } & \mathrm{CVCV}\end{array}$

\section{Outcome measures}

Language outcomes were obtained at 24 months of age and included receptive and expressive standardized vocabulary tests: Peabody Picture Vocabulary Test (PPVT) (Dunn \& Dunn, 2007) and Expressive One Word Vocabulary Test (EOWVT) (Martin \& Brownwell, 2010). The MacArthur Communicative Development Inventory (MCDI) (Fenson, Dale, Reznick, Bates, Thal, Hartung \& Reilly, 2007) was completed by parents, in order to gather a reported inventory of expressive vocabulary at 24 months. In addition, the Ages \& Stages Questionnaire was completed at different age intervals (7.5months, 10 months and 24 months) to gather a variety of information regarding social and motor development (Bricker, Squires, Mounts, Potter, Nickel, Twonbly \& Farrell, 1999). We decided to focus on the following expressive outcome measures: MCDI scores, mean length of utterance in morphemes (MLU), and number of word types. 


\section{$\underline{\text { Reliability }}$}

Outcome Measures:

Each test was scored individually by two different research assistants. If there were any discrepancy in the scores, they met to discuss and come to a final scoring agreement. Raw scores were used for the MCDI and for the PPVT, which is only normed for children older than 2 years and 6 months old; standard scores were used for the EOWVT.

\section{Transcription Reliability:}

Inter-rater reliability was completed by another graduate researcher, who was trained using the same transcription rules listed above. Two transcripts at each age interval $(7,10 / 11,18$, and 24 months) were randomly selected for this purpose, which is $16 \%$ of the total transcripts. We determined consonant agreement within each utterance. Inter-rater agreement percentages for 24 month transcripts were $92 \%$ and $79 \%, 18$ months $88 \%$ and $90 \%, 11$ months 84 and $81 \%$, and 7 months $88 \%$ and $84 \%$. To maintain consistency within the data, the initial transcriptions were used for final data analysis.

Intra-rater reliability was assessed by the original transcriber re-transcribing a portion of the sample. Eight-hundred and thirty-four utterances, approximately $12 \%$ of total utterances, were re-transcribed out of a total of 6796 utterances. Reliability was calculated using agreement per utterance and was found to be $94.6 \%$ reliable (789/834). 


\section{$\underline{\text { Statistical analyses }}$}

The first hypothesis of this study was that infants' syllable structure level mean at each age interval (7, 10/11 and 18 months) would be related to language outcomes at two years of age. Separate linear regressions were used to determine the relationship between mean SSL at 7.5, 10/11, and 18 months against three expressive language measures at two years of age: MLU, types, and MCDI.

The second hypothesis of this study was that infants' phonetic inventory at each age interval (7, 10/11 and 18 months) would be related to language outcomes at two years of age Separate linear regressions were used to determine the relationship between total phonetic inventory at 7.5, 10/11, and 18 months against three expressive language measures at two years of age: MLU, types, and MCDI.

As an additional hypothesis, we believed that there would be an increase in phonetic inventory and syllable structure mean across age intervals. Furthermore, we believed that inventory and SSL at each interval would be interrelated.

To determine if these relationships existed between these variables, correlational data was obtained between each measure (SSL mean and phonetic inventory) and language outcomes (MLU, types, and MCDI raw) at each age interval (7.5, 10/11, and 18 months). A Bonferroni correction was used to reduce the risk of a Type I error. As an additional post-hoc analysis, we decided to determine if group differences existed between our highest and lowest performing children in regards to their expressive language outcomes at two years of age and at three points in earlier development. Since we ran correlations between our variables (inventory and SSL) at earlier points and how they related to outcomes later, for this analysis, we wanted to explore outcomes and how they related to earlier points in development. Furthermore, the range of 
expressive outcome scores were larger (compared to inventory and SSL) and thus would be more informative compared to if we look at group differences in regards to inventory and SSL. To do this, we divided the cohort into the three groups ranked highest to lowest based on three 24 month expressive outcome measures (MCDI, MLU and types). We then used the top and bottom third of the sample in order to distinguish any major group differences within our sample. This resulted in each group having 16 participants. Each outcome measure was run as a separate analysis. Paired t-tests were used to compare language outcome scores from children with the highest and lowest scores at each age interval. Descriptive statistics were also obtained in order to describe the growth in phonetic inventory and mean syllable structure level longitudinally.

\section{Results}

\section{$\underline{\text { Longitudinal Data }}$}

One of the first analyses performed was obtaining descriptive statistics to longitudinally explore the development of phonetic inventory and mean syllable structure level. Mean values for total inventory and mean SSL were calculated for each age group. Descriptive statistics for inventory and mean SSL across age intervals is shown in Table 3 and 4. Correlation matrixes were completed to demonstrate the correlations between age groups. This was an exploratory analysis; therefore we used a $\mathrm{p}$ value of $\mathrm{p}<.05$ for significance.

As one would expect, inventory size increased across the age intervals, demonstrated by the increase in group means across ages. Our results show that inventory at 7.5 months positively correlated with inventory at 11 months $(r=.3312, \mathrm{p}=.0214)$; however, inventory at 7.5 months did not appear to significantly relate to inventory at any other age, though the general trend is positive. Interestingly, inventory at 11 months did not appear to relate to 18 months $(\mathrm{r}=.1842$, $\mathrm{p}=.2099)$, though it was related to inventory at 24 months of age $(\mathrm{r}=.2971, \mathrm{p}=0.0403)$. Inventory 
at 18 months, was highly and significantly correlated with inventory six months later, at 24 months $(\mathrm{r}=.7671 ; \mathrm{p}<.0001)$.

Similar to inventory, SSL increased across the age intervals; however, no significant relationships were found between one age and another. In fact, mean SSL at 7.5 months had a slightly negative correlation with SSL at 11 months $(r=.0101, p=.9463)$. Interestingly, the trend between SSL at 7.5 and 18 months is positively related and falls closer to significance $(\mathrm{r}=$ $.2777 ; \mathrm{p}=.0587)$. There were no significant relationship between SSL at 11 months and SSL at 18 months was found, though the general trend was positive $(r=.2011, p=.1754)$. These results suggest that syllable structure at one age does not necessarily predict syllable structure at another age; possible interpretations of these results are discussed below.

Table 3: Growth of Inventory across Age Intervals

\begin{tabular}{llll}
\hline Age & Mean & Std. Deviation & $N$ \\
\hline & & & \\
7 months & 8.98 & 6.08 & 48 \\
11 months & 13.27 & 6.20 & 48 \\
18 months & 24.15 & 7.97 & 48 \\
24 months & 31.38 & 5.29 & 48 \\
& & & \\
\hline
\end{tabular}

Table 4: Inventory across Age Intervals

\begin{tabular}{|c|c|c|c|c|}
\hline & 7 months & 11 months & 18 months & 24 months \\
\hline 7 month & ----- & $\begin{array}{l}\mathrm{r}=.3312^{*} \\
\mathrm{p}=.0214\end{array}$ & $\begin{array}{c}\mathrm{r}=.1537 \\
\mathrm{p}=.2971\end{array}$ & $\begin{array}{l}\mathrm{r}=.2416 \\
\mathrm{p}=.0981\end{array}$ \\
\hline 11 months & $\begin{array}{c}\mathrm{r}=.3312^{*} \\
\mathrm{p}=.0214\end{array}$ & ----- & $\begin{array}{c}\mathrm{r}=.1842 \\
\mathrm{p}=.2099\end{array}$ & $\begin{array}{l}\mathrm{r}=.2971^{*} \\
\mathrm{p}=.0403\end{array}$ \\
\hline 18 months & $\begin{array}{l}\mathrm{r}=.1537 \\
\mathrm{p}=.2971\end{array}$ & $\begin{array}{l}\mathrm{r}=.1842 \\
\mathrm{p}=.2099\end{array}$ & ----- & $\begin{array}{l}\mathrm{r}=.7671^{*} \\
\mathrm{p}<.0001\end{array}$ \\
\hline 24 months & $\begin{array}{r}\mathrm{r}=.2416 \\
\mathrm{p}=.0981\end{array}$ & $\begin{array}{l}\mathrm{r}=.2971^{*} \\
\mathrm{p}=.0403\end{array}$ & $\begin{array}{l}\mathrm{r}=.7671^{*} \\
\mathrm{p}<.0001\end{array}$ & ---- \\
\hline
\end{tabular}

Note: $p<0.05 *$ 
Table 5 : Growth of Mean SSL across Age Intervals

\begin{tabular}{llll}
\hline Age & Mean & Std. Deviation & $N$ \\
\hline 7 months & & & \\
11 months & 1.28 & .5122 & 48 \\
18 months & 1.57 & .2772 & 48 \\
& 2.03 & .3198 & $47^{*}$ \\
& & & \\
\hline
\end{tabular}

Note: *. One child was omitted due to no vocalizations during 18 month session

Table 6: Mean SSL across Age Intervals

\begin{tabular}{|l|l|l|l|}
\hline & Mean SSL 7 months & Mean SSL 11 months & $\begin{array}{l}\text { Mean SSL 18 } \\
\text { months* }\end{array}$ \\
\hline Mean SSL 7 months & ----- & $\begin{array}{l}\mathrm{r}=-.0101 \\
\mathrm{p}=.9463\end{array}$ & $\begin{array}{l}\mathrm{r}=.2777 \\
\mathrm{p}=.0587\end{array}$ \\
\hline Mean SSL 11 months & $\mathrm{r}=-.0101$ & ----- & $\mathrm{r}=.2011$ \\
& $\mathrm{p}=.9463$ & $\mathrm{p}=.1754$ \\
\hline $\begin{array}{l}\text { Mean SSL 18 } \\
\text { month* }\end{array}$ & $\mathrm{r}=.2777$ & $\mathrm{p}=.0587$ & $\mathrm{p}=.1754$ \\
\hline
\end{tabular}

Note: *One child was omitted due to no vocalizations during 18 month session; $\mathrm{N}=47$

\section{$\underline{\text { Relationship between phonological variables and 24-month language outcomes }}$}

To determine if any phonological measures were predictors of child language outcomes,

Pearson's product-moment correlations were performed between total inventory and mean SSL at each age interval (7.5, 11, and 18 months) and three language outcome measures (MCDI, types and MLU). A Bonferroni correction was used to reduce the risk of Type I error, which lowered the p-value to .0167 . We looked at each age interval as an individual hypothesis with three separate analyses associated with each. 
18 months

As expected, at eighteen months, total phonetic inventory and mean SSL were related to all selected expressive language outcomes (See Table 5). This analysis revealed a significant positive relationship between inventory and mean SSL and all expressive language outcomes (MCDI, MLU, and types) at 18 months. Our results suggest that total inventory is a better predictor than mean SSL. Correlations between inventory and the three outcomes were larger than those correlations between SSL and outcomes. Possible explanations are discussed below.

Table 7: 18 month Correlations between expressive language outcomes

\begin{tabular}{|l|l|l|l|}
\hline & MCDI & MLU & Types \\
\hline $\begin{array}{l}\text { Total Inventory 18 } \\
\text { months }\end{array}$ & $\begin{array}{l}\mathrm{r}=.5937 * * \\
\mathrm{p}<.0001\end{array}$ & $\begin{array}{l}\mathrm{r}=.7287 * * \\
\mathrm{p}<.0001\end{array}$ & $\begin{array}{l}\mathrm{r}=.7312^{* *} \\
\mathrm{p}<.0001\end{array}$ \\
\hline Mean SSL 18 months & $\begin{array}{l}\mathrm{r}=.4998^{* *} \\
\mathrm{p}<.0001\end{array}$ & $\begin{array}{l}\mathrm{r}=.5386^{* *} \\
\mathrm{p}<.0001\end{array}$ & $\begin{array}{l}\mathrm{r}=.4512 * * \\
\mathrm{p}=.0015\end{array}$ \\
\hline
\end{tabular}

Note: $* * \mathrm{p}<0.0167$

Figure 2: Inventory at 18 months and Outcomes

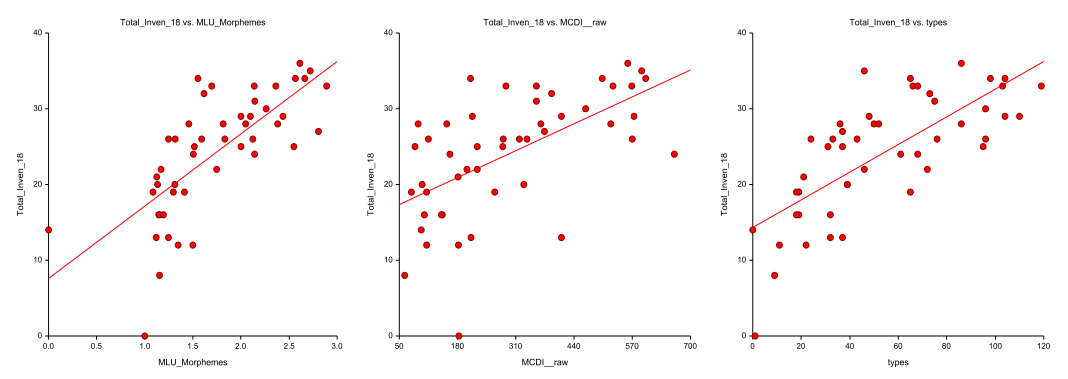


Figure 3: SSL at 18 months and Outcomes
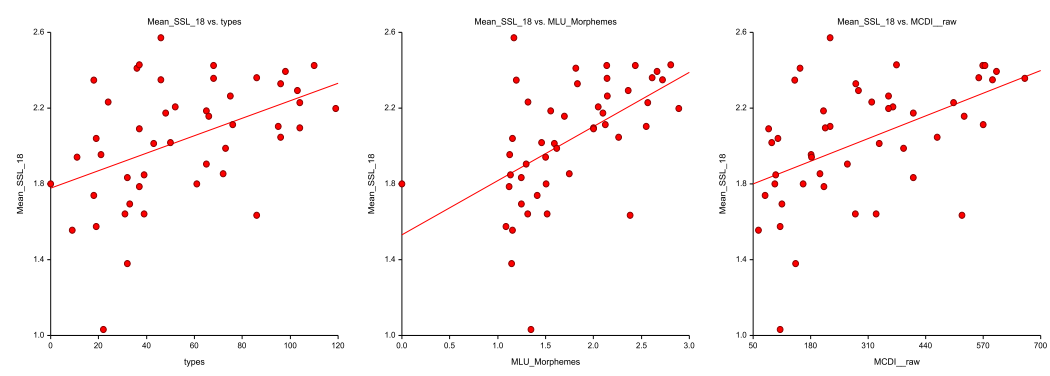

\section{1 months}

The next step in analyzing the data was to see if phonology at earlier ages were related to language outcomes at two years of age. This analysis revealed a significant positive relationship between total inventory at 11 months and all expressive language outcome measures (See Table 8). Mean SSL at 11 months did not significantly correlate with MCDI; however, there was a positive trend $(r=.2776, p=.0561)($ See Figure 6$)$. Mean SSL at 11 months revealed a significant positive relationship with types and MLU at two years of age $(r=.3457, p=.0161$; $\mathrm{r}=.4023, \mathrm{p}=.0046$ respectively). MLU and types are both expressive language measures obtained at a single moment in time whereas the MCDI is a perceived expressive vocabulary measure obtained from parental report that in essence captures the parent's impressions of cumulative language growth over time. These results indicate that the sounds and syllable shapes that a child produces at 11 months may be related to expressive language skills a full year later. 
Table 8: 11 month Correlations between expressive language outcomes

\begin{tabular}{|l|l|l|l|}
\hline & MCDI & MLU & Types \\
\hline $\begin{array}{l}\text { Total Inventory 11 } \\
\text { months }\end{array}$ & $\mathrm{r}=.3018$ & $\mathrm{r}=.0371$ & $\mathrm{p}=.0086$ \\
& $\mathrm{r}$ & $\begin{array}{l}\mathrm{r}=.4456^{* *} \\
\mathrm{p}=.0015\end{array}$ \\
\hline Mean SSL 11 months & $\mathrm{r}=.2776$ & $\mathrm{r}=.3457^{* *}$ & $\mathrm{r}=.4023^{* *}$ \\
& $\mathrm{p}=.0561$ & $\mathrm{p}=.0161$ & $\mathrm{p}=.0046$ \\
\hline
\end{tabular}

Note: $* * \mathrm{p}<0.0167$

Figure 4: Inventory at 11 months and outcomes
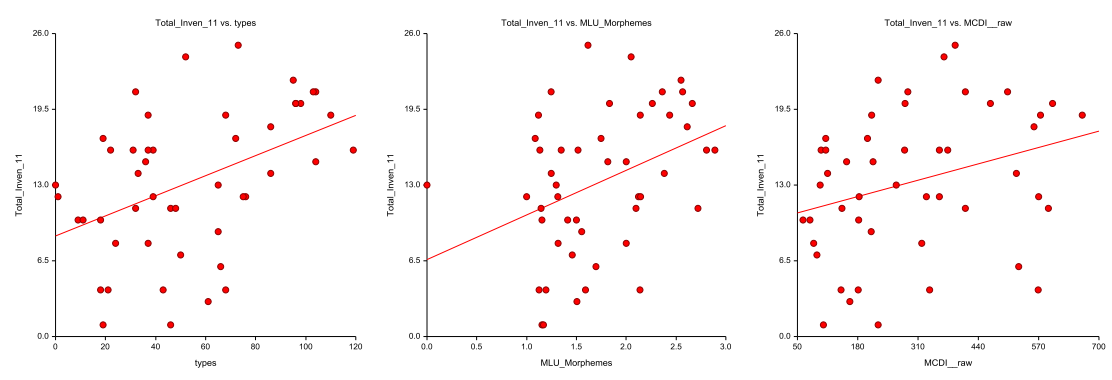

Figure 5: SSL at 11 months and outcomes
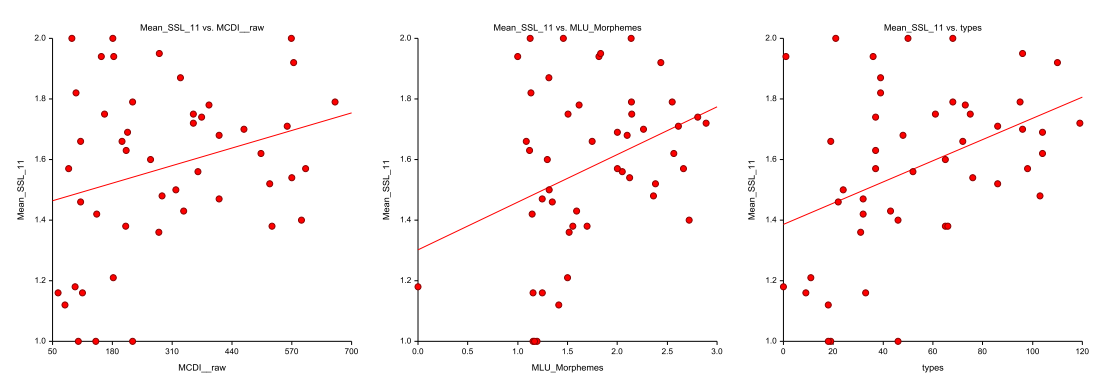

$\underline{7 \text { months }}$

Finally, we asked if we could find relationships between phonetic inventories and mean SSL at 7 months and 24 month expressive language outcomes. No significant correlations were found between both inventory and mean SSL and language outcomes, using the criterion of $p<$ .0167; however, the overall trend was positive (See Figures 8 and 9). Mean SSL at 7 months generally appeared to be more related to MLU $(r=.2499, \mathrm{p}=.0867)$ and types $(\mathrm{r}=.2987, \mathrm{p}=.0392)$ 
at two years of age than phonetic inventory (See Table 9). These results suggest that inventory and mean SSL at 7.5 months of age are not strongly predictive or related to expressive language outcomes at two years of age, although there is a positive relationship between these phonological and language measures.

Table 9: 7 month correlations between expressive language outcomes

\begin{tabular}{|l|l|l|l|}
\hline & MCDI & MLU & Types \\
\hline Total Inventory 7 months & $\mathrm{r}=.0724$ & $\mathrm{r}=.2151$ & $\mathrm{r}=.2442$ \\
$\mathrm{p}=.6248$ & $\mathrm{p}=.1420$ & $\mathrm{p}=.0943$ \\
\hline Mean SSL 7 months & $\mathrm{r}=.0699$ & $\mathrm{r}=.2499$ & $\mathrm{r}=.2987$ \\
& $\mathrm{p}=.6370$ & $\mathrm{p}=.0867$ & $\mathrm{p}=.0392$ \\
& & & \\
\hline
\end{tabular}

Note: No significant correlations were calculated

Figure 6: Inventory at 7 months and outcomes
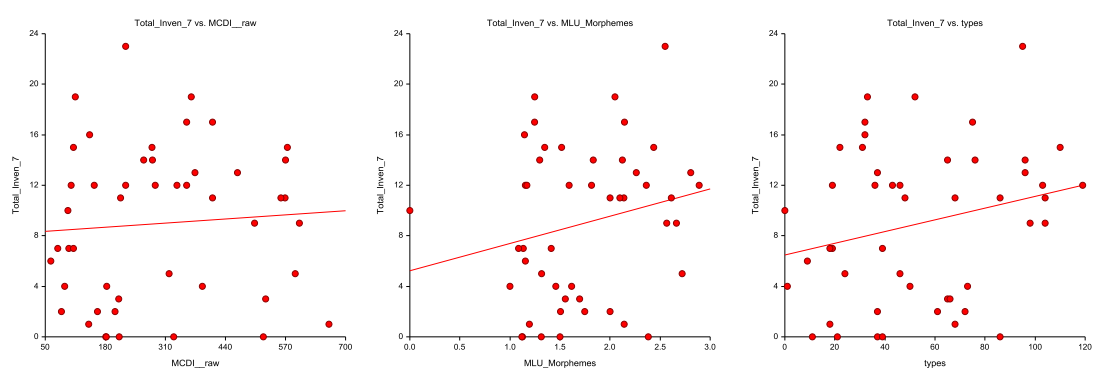

Figure 7: SSL at 7 months and outcomes
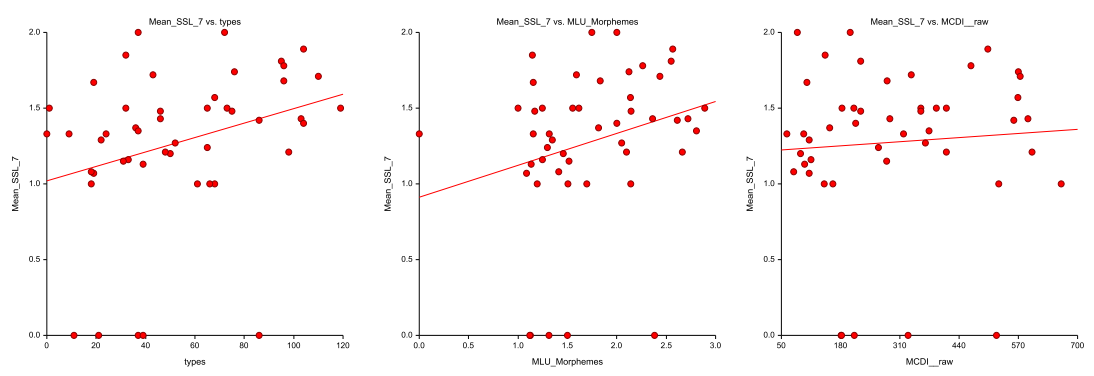
As a post-hoc analysis, we omitted those children did not vocalize at any age interval, resulting in zero inventory and zero SSL. Furthermore, we omitted those children who did not have any mappable lexical targets in their mother-child play session at 24 months (which is the activity that MLU and types outcome measures were extracted from). Correlations did not change meaningfully when omitting these individuals. All significant correlations obtained from the full sample were still significant with these participants excluded.

\section{Group comparisons of 24-month language outcomes}

In this post-hoc analysis, we asked whether children scoring highest and lowest in terms of 24 month language ability had earlier phonological profiles that were distinct. Our goal was primarily to see if children who performed less well on language measures as toddlers had shown different phonological inventories and SSL means at earlier points in development. To do this, we divided our cohort into three groups and used "high" and "low" groups; t-tests were completed in order to compare their total inventories and mean SSL at each age interval. Children were ranked based on their scores on MLU, MCDI, and types. The children with the sixteen highest scores were labeled as "high", while the children with the sixteen lowest scores were labeled as "low". The sixteen children with the median scores were excluded from the analysis. We decided to split our groups by their 24 month outcomes due to the limited range potential of our study variables. Both inventory and SSL have a limited range of potential values, and therefore, are not optimal for computing differences between groups of children; however, in our cohort, there was a wide range of scores on our three 24 month child language outcome measures. Therefore, we decided to explore the group differences between children's 24 month outcomes and how they differed in their inventories and SSL in earlier points in 
development. Each expressive outcome was run as a separate hypothesis. A Bonferroni correction was used to reduce the risk of a Type I error; alpha was set at $\mathrm{p}<.0167$.

Results suggest that children who had higher expressive language scores at two years of age had phonetic inventories and mean SSL scores that were higher than those children whose expressive language skills were lower at two years of age.

There were significant group differences at 18 months, in respect to inventory and SSL (See Table 10). Results show that those children with higher MLU at two years have significantly higher inventory and SSL at 18 months compared to those children with lower MLU scores. The only other significant group difference was found at 11 months in respect to total inventory; those children who had higher MLU at two years had inventories at 11 months of age that were significantly higher than the those children who had lower MLU at two years. Although the rest of the differences did not achieve significance, generally, children with the lowest expressive grammatical outcomes at age two (as measured by MLU) had both fewer phonemes in their inventory and less complex average syllable structure level at all earlier observation points. 
Table 10: MLU group comparisons

\begin{tabular}{llll}
\hline & Top MLU & Bottom MLU & t scores \\
\hline $\begin{array}{l}\text { Inventory Mean } \\
-7 \text { months }\end{array}$ & 11 & 8.13 & $\begin{array}{l}1.35 \\
(\mathrm{p}=.187)\end{array}$ \\
-11 months & 16 & 11 & $\begin{array}{l}2.55(\mathrm{p}=.016)^{*} \\
7.23(\mathrm{p}<.0001)^{*}\end{array}$ \\
-18 months & 30.44 & 16.81 & \\
Mean Syllable Shape & & & 1.67 \\
-7 months & 1.41 & 1.10 & $\begin{array}{l}(\mathrm{p}=.105) \\
(\mathrm{p}=.031)\end{array}$ \\
-11 months & 1.68 & 1.46 & $\begin{array}{l}3.78 \\
(\mathrm{p}=.001)^{*}\end{array}$ \\
-18 months & 2.24 & 1.88 & \\
\hline
\end{tabular}

Figure 8: 7 month MLU group comparisons: Inventory and Mean SSL
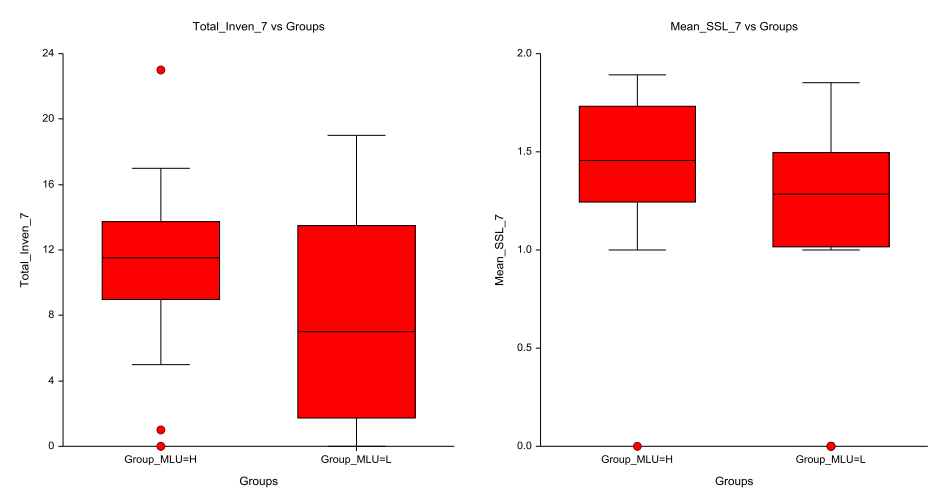

Figure 9: 11 month MLU group comparisons: Inventory and Mean SSL
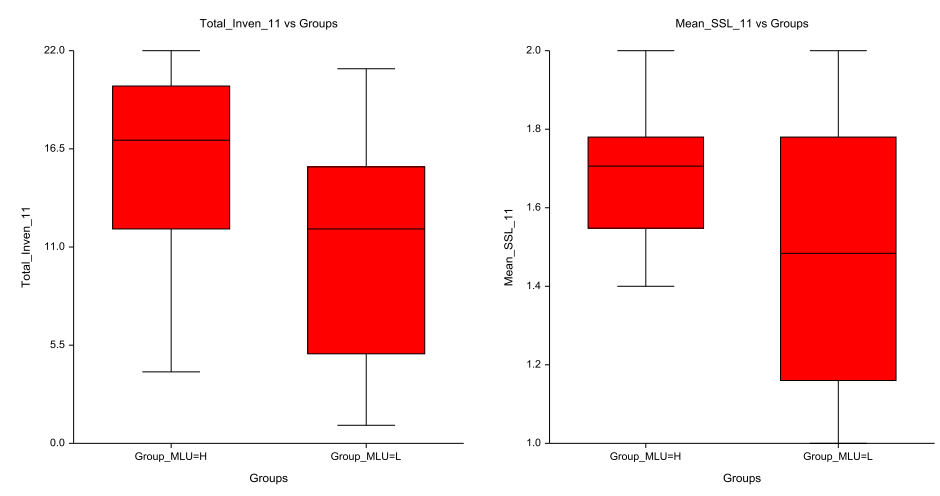
Figure 10: 18 month MLU group comparisons: Inventory and Mean SSL
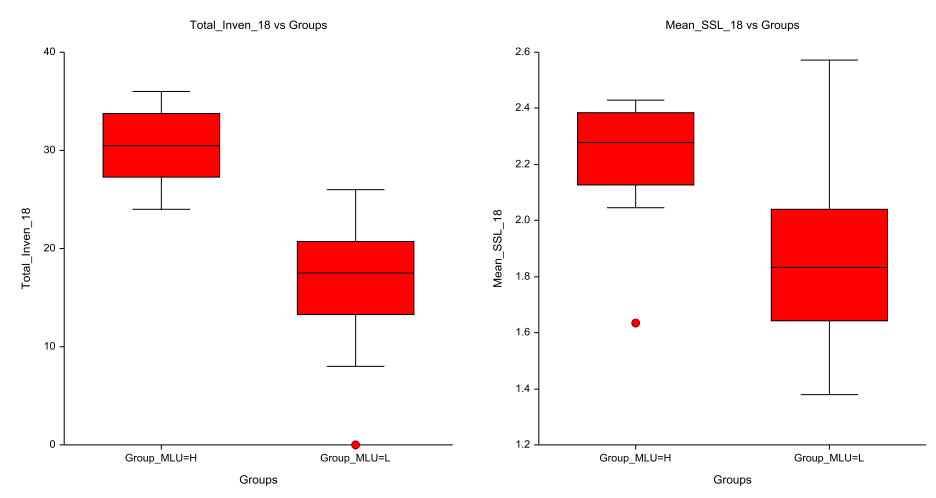

Similar patterns were seen for MCDI, the parental report of vocabulary growth. Results show that children who had higher MCDI scores at 24 months, had inventories and mean SSL at 18 months of age that were significantly higher than those children with lower scores on the MCDI at 24 months. No significant group differences were observed at 7 or 11 months in mean SSL at, indicating that MCDI scores may not be related to SSL during these earlier age intervals. Though no group difference was observed at 7 months in regards to inventory, a significant group difference was observed at 11 months in regards to inventory. Those children who had higher MCDI scores at 24 months, had inventories at 11 months that was significantly higher than those children who had lower MCDI scores. Results can be found in Table 11 and Figures 13 through 15. 
Table 11: Group Comparisons MCDI

\begin{tabular}{llll}
\hline & Top MCDI & Bottom MCDI & t scores \\
\hline $\begin{array}{l}\text { Inventory Mean } \\
-7 \text { months }\end{array}$ & 9.69 & 7.5 & 1.06 \\
- 11 months & 16.31 & 9.93 & $\begin{array}{l}(\mathrm{p}=.297) \\
(\mathrm{p}=.003)^{*}\end{array}$ \\
-18 months & 29.44 & 19 & $\begin{array}{l}5.07 \\
(\mathrm{p}<.0001)^{*}\end{array}$ \\
Mean Syllable Shape & & & 1.11 \\
-7 months & 1.35 & 1.15 & $(\mathrm{p}=.275)$ \\
& & & 1.83 \\
-11 months & 1.65 & 1.47 & $(\mathrm{p}=.077)$ \\
-18 months & 2.20 & 1.83 & $\begin{array}{l}3.54 \\
(\mathrm{p}=.001)^{*}\end{array}$ \\
\hline
\end{tabular}

Figure 11: 7 month MCDI group comparisons: Inventory and Mean SSL
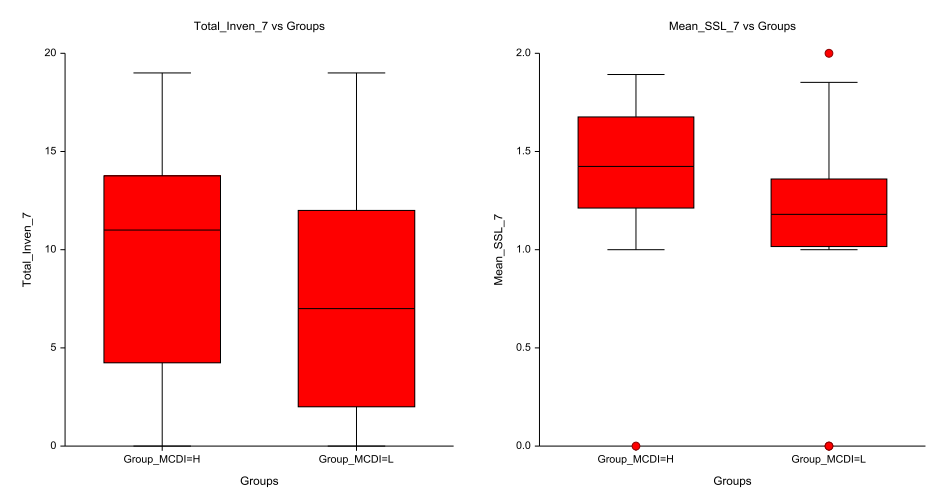

Figure 12: 11 month MCDI group comparisons: Inventory and Mean SSL
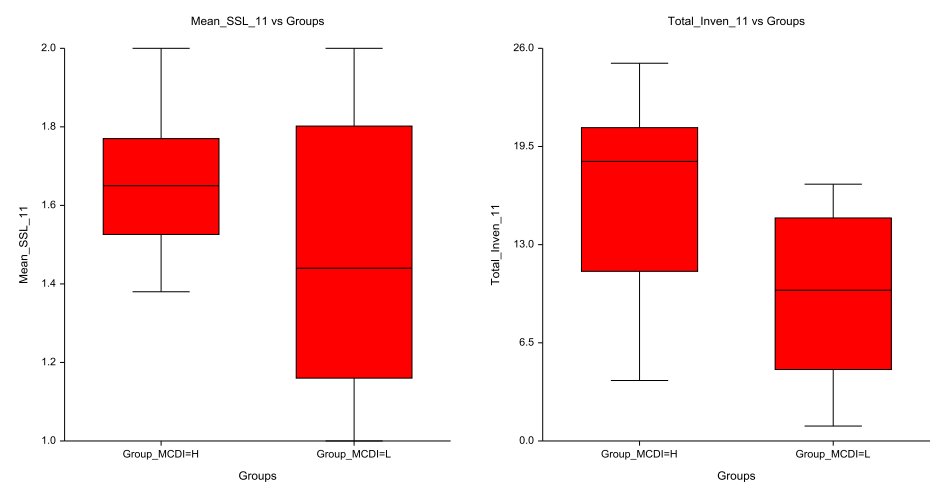
Figure 13: 18 month MCDI group comparisons: Inventory and Mean SSL
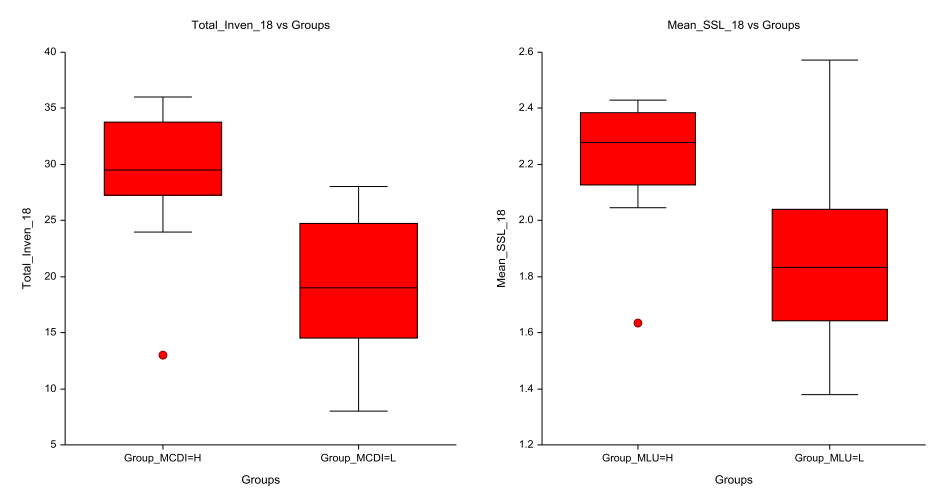

Finally, a similar profile was shown for expressive vocabulary during free play at 24

months. Results show that children with a higher number of word types at 24 months had significantly larger inventories and mean SSL at 11 and 18 months compared to those children who have fewer number of word types. There were no significant group differences observed at 7 months in either inventory or mean SSL although children with lower type counts at 24 months did have smaller inventories and less complex SSL means as 7 month old infants.

Table 12: Group Comparison Types

\begin{tabular}{lccc}
\hline & Top Types & Bottom Types & t scores \\
\hline $\begin{array}{l}\text { Inventory Mean } \\
-7 \text { months }\end{array}$ & 10.44 & 9.12 & $\begin{array}{l}.597 \\
(\mathrm{p}=.555)\end{array}$ \\
-11 months & 18.19 & 11.38 & $\begin{array}{l}4.23 \\
(\mathrm{p}<.0001)^{*}\end{array}$ \\
-18 months & 29.51 & 16.94 & $\begin{array}{l}5.95 \\
(\mathrm{p}<.0001)^{*}\end{array}$ \\
Mean Syllable Shape & & & 1.78 \\
-7 months & 1.47 & 1.16 & $(\mathrm{p}=.085)$ \\
& 1.69 & 1.41 & $\begin{array}{l}3.24 \\
(\mathrm{p}=.003)^{*}\end{array}$ \\
-11 months & & & 3.33 \\
& 2.16 & 1.81 & $(\mathrm{p}=.002)^{*}$ \\
\hline
\end{tabular}


Figure 14: 7 month types group comparisons: Inventory and Mean SSL
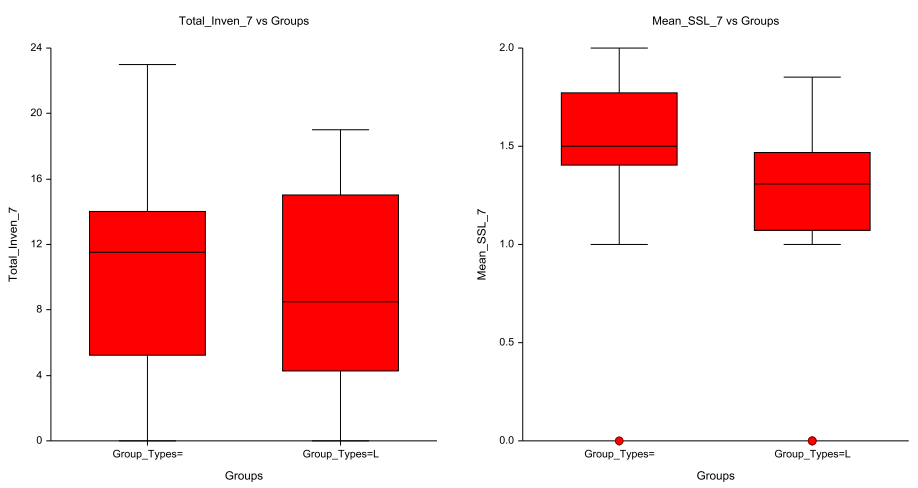

Figure 15: 11 month types group comparisons: Inventory and Mean SSL
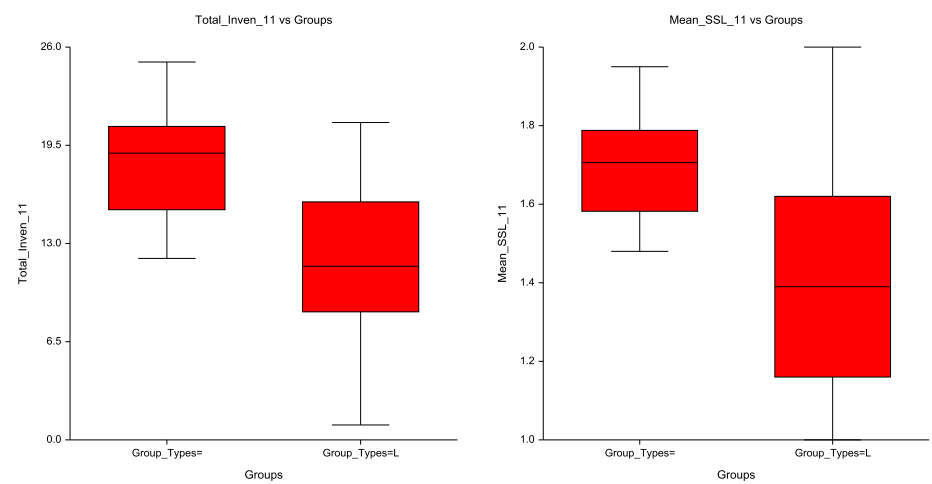

Figure 16: 18 month types group comparisons: Inventory and Mean SSL
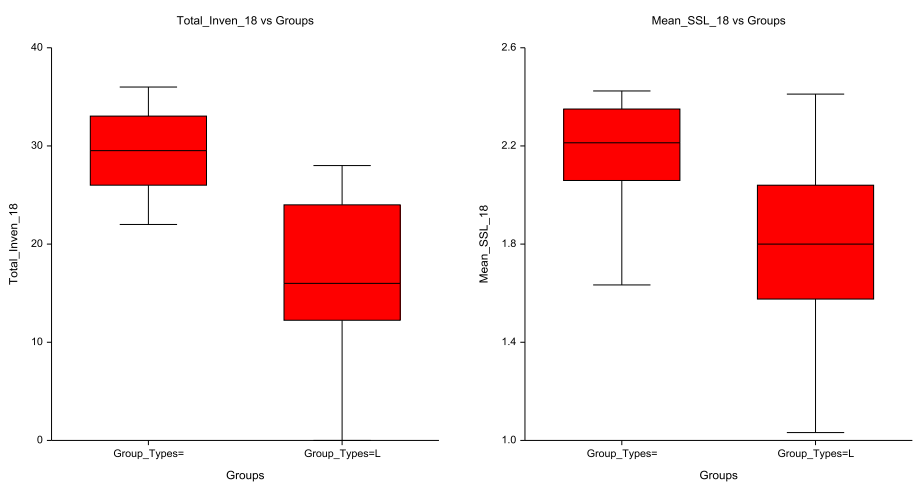


\section{Discussion}

The purpose of the present study was to determine if the phonological variables such as total phonetic inventory and mean syllable structure level at 7.5, 11, and 18 months were able to predict expressive language outcomes at 24 months of age. We also sought to determine if there were differences between groups in terms of earlier phonological profiles when stratifying our cohort into a "high" and "low" performing group based on expressive outcome measures (MLU, MCDI, and types), when the children reached 24 months of age. Analyses yielded several significant findings that further inform previously gathered data on these phonological variables.

Our longitudinal hypothesis was generally supported by our results, as both inventory and SSL increased as the child got older, as would be expected. The relationship between inventories across age intervals revealed interesting and slightly unexpected results. Inventory at 7 months of age was related to inventory at 11 months but no other age intervals. These findings may be due to the fact that children at 7 months of age are entering or currently in the canonical babbling stage and experimenting with speech-like syllables mixed with earlier marginal babbling and vocal play behaviors (Oller, 1980). The transcription of utterances at 7.5 and 11 months may have also been less reliable due to the difficulty in mapping child's early vocalizations and "shoe-horning" them into adult-like consonants and vowels (Ramsdell, Kimbrough, \& Ethington, 2007; Stockman, Woods, \& Tishman, 1981). This may explain why relationships between inventory at 7 months and 18 and 24 months did not reach significance; however, the overall trend between inventory at 7 months and later age intervals were positive, supporting the idea that inventory size at each age interval are related. Inventory at 11 months of age was not related to inventory at 18 months, but significantly related to inventory at 24 months, which is unexpected. One possible explanation for these findings may lie in the fact that other 
variables may be impacting the child at this point in development, as suggested previously in our discussion about a "transactional" hypothesis. Mediation from the environment may be influencing the child; for example, the child or mother's focus on particular items or communicative acts at this point in time may have affected the sample from which we computed the phonological profiles. As expected, we found a significant relationship between inventory at 18 and 24 months; at this point the child has begun to produce meaningful speech and thus has obtained a fair majority of the inventory of English phonemes between these two age intervals.

SSL increased across the age intervals; however, no significant relationships were found between one age and another. This finding was a bit perplexing, as one would expect there to be a relationship between the syllable structures a child produces earlier and later in development. SSL is expected to increase with increased language skills (Paul \& Jennings, 1992; Pharr et al., 2000). The typical development of syllable structure is from single sounds and CV or VC syllables, progressing to more complex syllables (i.e., CVC, CVCV, CCVC, etc.). One possible explanation for these findings is our choice to include both babbled utterances and meaningful utterances in our calculation of the mean SSL. For example, at 7.5 months, a child may have produced a babbled string [gidi], which would have been assigned a level 3 (containing two true consonants). This may have produced larger SSL scores than when the child started producing actual targets (i.e. [kæt], [koki]) at later age intervals; the combination of babbled strings and recognizable lexical targets may have obscured patterns seen in each category separately. This is one possible limitation of our current methodology. In fact, Morris (2010) suggests calculating separate measures for babbled utterances and meaningful utterances because children's phonological abilities may be more taxed when producing lexical targets compared to babbled 
vocalizations. Unfortunately, determining the child's possible lexical targets was not always possible given the use of audio to compute the phonological features of the child's utterances.

We predicted that children's total phonetic inventories and mean SSL at each age interval (7.5, 11, and 18 months) would be related to language outcomes at 24 months of age. This hypothesis was generally supported, with the exception of the 7.5 month data. At 18 months, phonetic inventory and mean SSL were significantly correlated with all expressive language outcomes (MLU, types, and MCDI), as predicted. We also expected that phonetic inventory mean SSL at 18 months would positively correlate with language outcomes because the child had more sounds to combine into a variety of syllable shapes and map onto meaning (StoelGammon 1989). Phonetic inventory and mean SSL at 11 months significantly correlated with expressive language outcomes at 24 months of age. McCathren, Yoder \& Warren (1999) found that inventory size in children from 17-34 months was highly correlated with vocabulary size (types) that was examined 12 months later from the initial assessment. Our findings suggest that even as early as 11 months of age, inventory size is related to expressive language outcomes 13 months later. No significant results were found at 7.5 months, suggesting that this may be too early an age at which to predict later performance. Our results suggest that phonological abilities as early as 11 months of age may be predictive of language development and/or outcomes at 24 months of age.

Across our age intervals, inventory was consistently more related to language outcomes than was SSL. This may be related to the possible inflation of SSL by use of a maximum bracketing strategy in coding, and inclusion of both babbled utterances and lexical targets. The relationships between SSL at each age may have been obscured and resulted in inventory, which is less subjective in this regard, emerging as a more informative predictor of later language skills. 
The more sounds that children have in their inventories, the more sounds they are able to combine to display more advanced outcomes at 24 months of age. It would be informative in future studies to separate babbled utterances and lexical targets when calculating SSL measures and determine if the child's SSL profiles correlate with future outcomes with this adaptation. Our other hypothesis was that those children with higher expressive language scores (MCDI, MLU, and types) at 24 months of age would have higher total inventories and mean SSL at earlier points in development. Significant findings emerged from this analysis. Generally speaking, those children who had more superior expressive language outcomes at 24 months had higher total inventories and mean SSL at 11 and 18 months compared to those children who had lower outcomes at 24 months. Our results suggest that there is a strong relationship between the number of word types a child has at 24 months of age and inventory and SSL at 11 and 18 months, compared to MCDI and MLU. The analysis revealed that inventory and mean SSL at 7 months was not related to expressive language outcomes at 24 months of age; however, it did reveal a strong relationship between the child's phonological abilities at 11 and 18 months and how they perform a year and six months later, respectively. Although we cannot determine the directionality of this relationship, prior findings suggest that children's phonological abilities may be predictive of later language outcomes (Oller, Eilers, Neal, Schwartz, 1999; McCathren, Yoder \& Warren, 1999). Logically, a child with a larger repertoire of sounds and syllable shapes would be better equipped to produce more words and more complex utterances, skills measured by the outcomes we chose.

Across all of our analyses, MLU and types in the child's spontaneous language at 24 months appeared to be more related to our phonological variables than MCDI scores at 24 months of age. Each of these measures are related to expressive language; however, MCDI is a 
perceived measure of the child's global expressive vocabulary across time and contexts, whereas MLU and types are "snapshot" measures, collected at one point in time during a single set of tasks. Parental report of their child's gradually accumulated expressive vocabulary may not be as related to these sensitive phonological measures. Furthermore, the environment in which we collected our sample may not necessarily demand the child to display their full linguistic repertoire. Types and MLU may be more related to inventory and SSL, as these are both extracted from spontaneous measures. If a child does not have the sounds or phonotactic skills necessary for some morphemes/allomorphs, this would lead to lower MLU. Additionally, if the child has more limited sounds in their repertoire, they are limited in the syllable structures they can produce that to identifiable types during transcription.

As mentioned previously, our cohort had no known risk factors for language delay and/or disorder; however, significant differences were found between top and bottom performing children based on expressive language outcomes at two years. Our "high" language users had an average MCDI score of 506 with a standard deviation of 92.05 . This score is roughly at the $85^{\text {th }}$ percentile for typically developing toddlers (both genders) at 24 months (Fenson et al., 2007). Our "low" language users had an average MCDI score of 120 with a standard deviation of 36.84. This score lies between the $15^{\text {th }}$ and $20^{\text {th }}$ percentile for typically-developing children, below average, but not in the clinical range of scores. Children who were "low" language users at age two (based on MCDI scores for this example) were found to have an average of 9.94 phonemes (SD:5.08) in their inventory and an average mean SSL of 1.46 (SD: .359) at 11 months of age, which was significantly less than those children who were "higher" language users. Therefore, we might recommend that, if a child's phonological abilities fall below the performance of our 
typically-developing "low" performers, these children may warrant monitoring for delay or disorder.

These group analyses replicated findings that syllable shape and inventories can be significantly different among groups of children (typically developing versus disorder/delayed or high and low performing toddlers, as in the present study) (Rescorla \& Ratner, 1996; Lambrecht, Roberts, Locke \& Tozer, 2010; Pharr, Ratner, \& Rescorla, 2000). Whereas most studies have explored the phonological abilities of children ranging from 17-36 months (McCathren, Yoder \& Warren, 1999; Rescorla \& Ratner, 1996; Lambrecht, Roberts, Locke \& Tozer, 2010; Pharr, Ratner, \& Rescorla, 2000),our present study found group differences between the top and bottom performing children on expressive outcomes measures and their total inventory and SSL means more than a year earlier. Additionally, our results suggest that a child's phonological abilities at 11 months of age may be predictive of language outcomes. The phonological profiles of typically-developing children explored at 11 months in the present study, may be clinically informative of profiles of delay and/or disorder.

\section{Clinical implications}

Our results suggest that measures such as phonetic inventory and mean syllable structure can be predictive of toddlers' later language outcomes at as early as 11 months of age; therefore, these measures may be used to monitor those children who appear delayed and/or disordered in order to intervene more quickly. The use of mean SSL and total phonetic inventory can also be used clinically to select lexical targets when programming for therapy with toddlers (Morris, 2010). An understanding of the child's inventory and the syllable structure they are able to produce can aid in selecting new lexical targets that the child is not likely to produce without 
treatment. Because we could not easily determine some of the children's lexical targets during these analyses, it was not possible to compute percent consonants correct (PCC), a measure of articulation accuracy. This is an obvious and valuable set of analyses that would provide further insights at a later time. As mentioned previously, children often produce words that have sounds in their repertoire; even if the sound is produced as an error for a target (Vihman, Macken, Miller, Simmons, \& Miller 1985). The SLP may utilize this information in order to expose the child to new sounds and syllable shapes to expand their phonological repertoire or prompt the child to use the target phoneme more accurately in other contexts; however, further investigation into the utility and reliability of using inventories and syllable structure patterns before one year of age to predict and guide work with toddlers at possible or evident risk for language delay is needed (Morris, 2009).

Finally, our measures were obtained from naturalistic observation. Goldstein \& Schwade (2008) found that infants nine and a half months old were able to learn new phonological vocal patterns when their mothers responded contingently to their infants' babbling (i.e., responding right away to their infants' babble versus delayed response). They found that social feedback did in fact facilitate vocal productions in infants at 9.5 months of age. Therefore, increased social feedback may aid children's development and provides better models for them to learn and produce phonological patterns that may facilitate further expressive language development. This concept is relevant to intervention and may in fact be relevant to understanding why some of the study children had larger or more restricted inventories if we can isolate profiles of interactions in the study mothers that appear to relate to their children's phonological skill development. 


\section{$\underline{\text { Limitations }}$}

A significant limitation of this study lies in the use of data that were obtained and analyzed at a later time using audio files. This limited our ability to identify phonetic targets in some cases. Without the use of video, it is difficult to identify target words that a child is referring to at a given time during the collected mother-child play sessions. Some studies restricted the inclusion of tokens to have one or two repetitions of a specific vocalization (Paul \& Jennings, 1992), whereas other studies have included all vocalization attempts (Pharr et al., 2000). Future investigations of phonological development should ensure that mother-child play sessions are video-recorded in order to map the child's vocalizations to target referents (in order to make accuracy judgments) as well as make more informed inclusion judgments.

Another possible limitation in this study was that we did not eliminate the use of repeated identical vocalizations, which may have inflated mean SSL due to credit being given for multiple repetitions of the same utterance; however, this would have also limited the number of tokens in our total analysis. Further study could contrast findings if exact repetitions were excluded, as well as explore the relationship between vocalization rate in conjunction with our current phonological variables and number of word types to determine if a relationship exists.

The duration of our play sessions may have not been adequate to get a maximum independent analysis of every child; however, Crary (1983) explored the influence of increasing sample size on phonological analyses from spontaneous speech and found that samples of 50 words provided descriptive information similar to samples of 100 words. Therefore, even though most of the samples have few utterances in the earlier age ranges, we believe that our findings suggest the informativeness of additional studies using larger speech samples. 


\section{Directions for future research}

We selected our cohort from a larger longitudinal study based on those children that had completed mother-child transcripts at each age interval (7.5, 10 or 11, 18, and 24 months). All of the children included in the present study had MCDI scores higher than fifty words at two years of age, and did not qualify as late-talking toddlers. There are approximately four children from the main study that obtained a score of 50 or fewer words on the MCDI; late-talkers are classified as have fewer than 50 words and no two-word combinations (Rescorla, 1989). Future analysis could be completed with these children as well as others who appear to be at-risk for language delay or disorder to determine clinically-relevant relationships between phonetic inventory and syllable shapes produced at different age intervals and 24 month language

outcomes. It would be interesting to see if the results with the typically-developing cohort could be replicated with children whose language outcomes are characteristic of delay or disorder. Furthermore, it would be clinically informative to relate our phonological variables at the earlier age intervals with additional communicative outcomes at 24 months, including percent consonants correct and scores on Goldman-Fristoe Test of Articulation (Goldman, 1969), since the GFTA is used to identify children in need of phonological intervention after age two. 


\section{References}

Aguilar-Mediavilla, E., Sanz-Torrent, M., \& Serra-Raventos, M. (2002). A comparative study of the phonology of pre-school children with specific language impairment (SLI), language delay (LD) and normal acquisition. Clinical Linguistics \& Phonetics, 16, 8, 573-596.

Bricker, D., Squires, J. (1999) Ages \& Stages Questionnaire: A Parent-Completed, ChildMonitoring System: Second Edition. Paul H. Brookes Publishing Co.

Crary, M. A. (1983). Phonological process analysis from spontaneous speech: The influence of sample size. Journal of Communication Disorders, 16, 2, 133-141.

Dethorne, L. S., Johnson, B. W., \& Loeb, J. W. (2005). A closer look at MLU: What does it really measure?. Clinical Linguistics \& Phonetics, 19, 8, 635-648.

Dunn, L.M. \& Dunn, D.M. (2007). Peabody Picture Vocabulary Test: Fourth Edition. Minneapolis: Pearson Assessments.

Fasolo, M., Majorano, M., \& D'Odorico, L. (2008). Babbling and first words in children with slow expressive development. Clinical Linguistics and Phonetics, 22, 2, 83-94.

Fenson, L., Dale, P. S., Reznick, J. S., Thal, D., Bates, E., Hartung, J. P., Pethick, S., \& Reilly, J. (2007). The MacArthur Communicative Development Inventories, $2^{\text {nd }}$ ed. Baltimore, MD: Paul H. Brokes Publishing Co.

Goldman, R. (1969). Goldman-Fristoe test of articulation. Circle Pines, Minnesota: American Guidance Service.

Goldstein, M. H., \& Schwade, J. A. (2008). Social feedback to infants' babbling facilitates rapid phonological learning. Psychological Science, 19(5), 515-523.

Harding, C. (1984). Acting with intention: A framework for examining the development of the intention to communicate. The origins and growth of communication, 123-135.

Jakobson, R. (1941). Kindersprache, Aphasie und allgemeine Lautgesetze. Upp-sala.

[Translated by Allan R. Keiler: Child language, aphasia, and phonological universals. The Hague: Mouton, 1968.]

Locke, J. L. (1983). Phonological acquisition and change. Academic Pr.

Locke, J. L. (1989). Babbling and early speech: continuity and individual differences. First Language, 9 191-206. 
Lambrecht, S. S., Roberts, J., Locke, J., \& Tozer, R. (2010). An exploratory study of the development of early syllable structure in reading-impaired children. Journal of Learning Disabilities, 43, 4, 294-307.

MacWhinney, B. (n.d.). CLAN. Pittsburgh, Pennsylvania: Carnegie Mellon University. Retrieved from childes.psy.cmu.edu/clan/

Maekawa, J., \& Storkel, H. L. (2006). Individual differences in the influence of phonological characteristics on expressive vocabulary development by young children. Journal of Child Language, 33(03), 439-459.

Martin, N. A. \& Brownell, R. (2010). Expressive One Word Picture Vocabulary Test. Novato, CA: ATP Assessments.

McCathren, R. B., Yoder, P. J., \& Warren, S. F. (1999). The relationship between prelinguistic vocalization and later expressive vocabulary in young children with developmental delay. Journal of Speech, Language, and Hearing Research, 42(4), 915-924.

McCune, L. (1992). First words: a dynamic system view. In C.A. Ferguson, L. Menn, \& C. Stoel-Gammon (Eds.) Phonological development: Theory, research, and implication, (pp. 313-336). Parkton, MD: York Press.

Morris, S. R. (2009). Test-retest reliability of independent measures of phonology in the assessment of toddlers' speech. Language, Speech, and Hearing Services in Schools, 40, $46-52$.

Morris, S. R. (2010). Clinical application of the mean babbling level and syllable structure level. Language, Speech, and Hearing Services in Schools, 41, 2, 223-30.

Oller D.K. (1980). The emergence of the sounds of speech in infancy. Child Phonology, Vol 1: Production, eds Yeni-Komshian G, Kavanagh J, Ferguson C (Academic, New York), 93-112.

Oller, D. K., Eilers, R. E., Neal, A. R., \& Schwartz, H. K. (1999). Precursors to speech in infancy: the prediction of speech and language disorders. Journal of Communication Disorders, 32, 4, 223-245.

Oller, D. K., \& Lynch, M. P. (1992). Infant vocalizations and innovations in infraphonology: Toward a broader theory of development and disorders. Phonological development: Models, research, implications, 509-536.

Oller, D. K., Wieman, L., Doyle, W., \& Ross, C. (1976). Infant babbling and speech. Journal of Child Language, 3, 1-11.

Oller, D. K., Niyogi, P., Gray, S., Richards, J. A., Gilkerson, J., Xu, D., \& Warren, S. F. (2010). Automated vocal analysis of naturalistic recordings from children with 
autism, language delay, and typical development. Proceedings of the National Academy of Sciences, 107(30), 13354-13359.

Paul, R., \& Jennings, P. (1992). Phonological behavior in toddlers with slow expressive language development. Journal of Speech, Language, and Hearing Research, 35(1), 99-107.

Pharr, A. B., Ratner, N. B., \& Rescorla, L. (2000). Syllable structure development of toddlers with expressive specific language impairment. Applied Psycholinguistics, 21(04), 429449.

Ramsdell, H. L., Kimbrough Oller, D., \& Ethington, C. A. (2007). Predicting phonetic transcription agreement: Insights from research in infant vocalizations. Clinical linguistics \& phonetics, 21(10), 793-831.

Rescorla, L. (1989). The Language Development SurveyA Screening Tool for Delayed Language in Toddlers. Journal of Speech and Hearing Disorders, 54(4), 587-599.

Rescorla, L. ( 2011). Late talkers: do good predictors of outcome exist?. Developmental Disabilities Research Reviews, 17, 2, 141-150.

Rescorla, L., Ratner N., (1996). Phonetic profiles of toddlers with specific expressive language impairment (SLI-E). Journal of Speech and Hearing Research, 39, 153-165.

Rose, Y., MacWhinney, B., Byrne, R., Hedlund, G., Maddocks, K., O’Brien, P., \& Wareham, T. (2006). Introducing Phon: A software solution for the study of phonological acquisition. In Proceedings of the 30th Boston University Conference on Language Development (pp . 489-500).

Stockman, I. J., Woods, D. R., \& Tishman, A. (1981). Listener agreement on phonetic segments in early infant vocalizations. Journal of Psycholinguistic Research, 10(6), 593-617.

Stoel-Gammon, C. (1985). Phonetic Inventories, 15-24 MonthsA Longitudinal Study. Journal of Speech, Language, and Hearing Research, 28(4), 505-512.

Stoel-Gammon, C. (1989). Prespeech and early speech development of two later talkers. First Language, 9, 207-224.

Stoel-Gammon, C. \& Sosa, A. V. (2007). Phonological development. In E. Hoff \& M. Schatz(eds), Handbook of child language, 238-56. Oxford: Blackwell Publishing Ltd.

Stoel-Gammon, C. (2011). Relationships between lexical and phonological development in young children, Journal of Child Language, 38, 1-34.

Vihman, M. M., \& Greenlee, M. (1987). Individual differences in phonological development: ages one and three years. Journal of Speech and Hearing Research, 30, 4, 503-21. 
Vihman, M. M., Macken, M. A., Miller, R., Simmons, H., \& Miller, J. (1985). From babbling to speech: a re-assessment of the continuity issue. Language, 61, 2, 397-445.

Whitehurst, G. J., Smith, M., Fischel, J. E., Arnold, D. S., \& Lonigan, C. J. (1991). The continuity of babble and speech in children with specific expressive language delay. Journal of Speech, Language, and Hearing Research, 34(5), 1121-1129. 